\title{
Development
}

\section{Building research capacity in Australian departments of general practice and rural health: a document review of annual reports}

Ellen McIntyre Associate Professor and Manager, Primary Health Care Research and Information Service, Department of General Practice, Flinders University, Adelaide, Australia, Deborah Saltman Professor, Discipline of General Practice, PHCRED Co-ordinator, University of Sydney, New South Wales, Australia, Vanessa Traynor Program Coordinator, PHCRED Program, School of Public Health and Community Medicine, University of New South Wales, Sydney, Australia, Jane Sims School of Physiotherapy, University of Melbourne, Victoria, Australia, Jeffrey Richards Department of General Practice, Monash University, Victoria, Australia ${ }^{\dagger}$ and Joanne Dollard Discipline of General Practice, University of Adelaide, South Australia, Australia

\begin{abstract}
Aim: To describe the scope and nature of research capacity building activity within academic departments of general practice and rural health in Australia. Method: Document review of Annual Reports for the years 2000 and 2003 of 17 university departments of general practice and rural health, funded through the Research Capacity Building Initiative (RCBI) of the Primary Health Care Research, Evaluation and Development (PHCRED) Strategy. Results: The review indicated that from 2000 to 2003, departments increased their activities in all areas of research capacity building activities. Mentoring and/or supervision other than higher degree students increased from 14 in 2000 to 266 in 2003. Twenty-two research networks involving over 1377 participants were operating in 2003. All departments were involved in collaborations either as part of grant applications, research projects or educational activities. Over 3630 people participated in 189 educational activities in 2003 compared to over 624 people attending 103 activities in 2000. Compared to $\$ 10.98$ million in 2000, departments had obtained more than $\$ 15.6$ million for research projects in 2003 . While there were more peer reviewed papers published in $2000(n=178)$ compared to 2003 $(n=130)$, these 17 departments gave 187 conference presen-tations. Conclusions: This review shows that the RCBI has contributed towards a considerable increase in research activities in these university departments of general practice and rural health. This has provided a major boost to primary health care research in Australia. These activities would have been unlikely to occur without the support and assistance of the PHCRED Strategy. Clearly, the full impact of the RCBI will take some time to evolve.
\end{abstract}

Key words: academic general practice; primary health care; research capacity building; research effort; research networks

Received: February 2006; accepted: October 2006

\author{
Address of correspondence: Ellen McIntyre, Associate \\ Professor, Primary Health Care Research and Information \\ Service (PHC RIS), Department of General Practice, Flinders \\ University, GPO Box 2100, Adelaide, SA 5001, Australia. \\ Email: ellen.mcintyre@flinders.edu.au \\ $\dagger$ : Deceased
}

(C) 2007 Cambridge University Press

\section{Introduction}

The Primary Health Care Research, Evaluation and Development (PHCRED) Strategy, funded by the Australian Government Department of 
Health and Ageing, seeks to embed a research and evaluation culture in Australian primary health care. Arising from the Wills (Department of Health and Aged Care, 1999) and General Practice Strategy Review Group Reports (Department of Health and Aged Care, 1998), this Strategy aims to both develop research capacity and the fields of knowledge that support the evidence base for general practice and primary health care services.

Elements of the PHCRED Strategy include the following:

- A research priority setting process for primary health care.

- Research capacity building initiative (RCBI) for university departments of general practice and rural health.

- The Australian Primary Health Care Research Institute (APHCRI).

- National Health and Medical Research Council (NHMRC) Primary Health Care Project Grants, Fellowships and Scholarships.

This article focuses on the RCBI of the Strategy, which was rolled out nationally in 2001. The aim of the RCBI is to 'support University Departments of General Practice and Rural Health to provide training and support in primary health care research, particularly among local practitioners' (RCBI, 2006). To achieve this, non-competitive funding (\$AUD200000/year) has been provided to academic departments of general practice and rural health across Australia to implement a range of capacity building strategies and activities with primary health care professionals (PHC RIS, 2006).

While there has been some attempt in the Australian literature to discuss what can or should be done through the RCBI (Farmer and Pilotto, 2001; Van Der Weyden, 2001; Gunn, 2002; Askew et al., 2002; Dunbar et al., 2002; Shah et al., 2002; Beacham et al., 2003; Jones et al., 2003), to our knowledge this is the first time that actual activity through the Initiative has been reviewed and presented.

The aim of this report was to review the key capacity building activities undertaken by 17 university departments of general practice and rural health in $2003-3$ years into the programme and to compare these patterns with those apparent in 2000, before funding commenced.

Primary Health Care Research and Development 2007; 8: 3-11

\section{Methods}

A document review of the 2000 and 2003 annual reports from RCBI funded academic departments of general practice and rural health was undertaken. Copies of these reports (produced as part of RCBI contract requirements) were provided by the Australian Government Department of Health and Ageing. Individual departments gave permission to use the material in a non-identifiable and aggregated manner. Any sensitive material was removed prior to receipt by the researchers.

Information regarding departmental activities was reviewed and aggregated under the following broad categories, derived from those listed in the departmental funding agreement reporting proforma:

- academic teaching

- research supervision and mentoring (number of $\mathrm{PhD}$, Masters and other students)

- research networks (number and type)

- educational research activities (number and type)

- collaborations (number and type)

- research funding (number of grants and total amount of funding)

- research effort (publications and presentations).

Because the reporting pro-forma differed in 2000 from 2003, some data was not collected in 2000 that was collected in 2003.

Information about the 2003 research projects (based on their titles) was categorized according to the National Health Priorities and the Primary Health Care Research Priorities (Kalucy et al., 2001). At the time of the review, the National Health Priorities included: cardiovascular diseases, mental health, cancer, asthma, injury and diabetes (National Health Priority Areas Initiative, 2006). The Primary Health Care Research Priority areas were: evidence-based practice, quality of care, models of service delivery, integration, economic issues, illness prevention and health promotion and health inequalities (Kalucy et al., 2001).

\section{Results}

All annual reports of the 17 departments receiving RCBI funding in 2003 were analysed as were the 2000 baseline annual reports. Ten reports were 
Table 1 University departments funded under the $\mathrm{RCBI}$

New South Wales

Department of General Practice, University of Newcastle Department of General Practice, University of Sydney Department of Rural Health, University of Sydney School of Public Health and Community Medicine, University of NSW

Northern Territory

Centre for Remote Health, Flinders University and Charles Darwin University

Queensland

Centre for General Practice, University of Queensland

Mt Isa Centre for Rural and Remote Health, James Cook University

Rural Health \& Workforce Research Unit, James Cook University

South Australia

Department of General Practice, Adelaide University Department of General Practice, Flinders University Spencer Gulf Rural Health School, University of South Australia

Tasmania

Discipline of General Practice, University of Tasmania University Department of Rural Health, University of Tasmania

Victoria

Department of General Practice, Monash University

Department of General Practice, University of Melbourne

Western Australia

Combined Universities Centre for Rural Health

Department of General Practice, University of WA

from university departments of general practice and seven were from departments of rural health (Table 1). Departments varied in size and age from those just starting up a department to well established departments. Table 2 gives a breakdown of the research capacity building related activities of these departments in both 2000 and 2003.

With regard to implementation of activities, it is worth noting that in eight of the programmes indicated, there had been RCBI staff changes in 2003. In some departments, this concerned several staff. The situation was compounded by long delays in the appointment of new staff.

\section{Academic teaching}

Departments continued to contribute to teaching in academic courses ranging from undergraduate degrees and Associate Diplomas, to Graduate Certificates, Graduate Diplomas, Honours degrees,
Masters degrees and $\mathrm{PhD}$ coursework. Teaching occurred in the disciplines of general practice, medicine, public health, health promotion, allied health, clinical practice and clinical epidemiology.

\section{Research supervision and mentoring}

Research supervision and mentoring has increased substantially. Supervision and mentoring occurred in some form in all departments in 2003 compared to only 11 departments in 2000. In 2003, 9 of the 17 departments supervised a total of $43 \mathrm{PhD}$ students. Although there were fewer Masters students $(n=8)$, departments reported a significant number of other students being mentored $(n=$ 266), including those undertaking other higher degrees, general practitioner (GP) registrars, clinic attendees, grant and bursary holders and others not enrolled in a formal course.

\section{Research networks}

While data on research networks specifically was not available in 2000, there appear to have been some networks operating in the more established departments. In 2003, 22 research networks involving over 1377 people were reported to have been established across 13 departments in 2003. These ranged from internal networks for staff to broader networks incorporating primary health care practitioners and students interested in research at various levels. Some research networks were set up with a specific task in mind while others were set up with a broader research focus. However, most used the network infrastructure to promote and conduct research activities such as workshops, research meetings, funding opportunities as well as providing a mentoring service.

\section{Research activities}

Educational research activities comprised a substantial component of RCBI activities. Over 3639 people participated in 189 activities in 2003 compared to $624+$ people attending 103 activities in 2000. Further detail on these activities was unavailable in the 2000 reports, so no qualitative comparison was possible.

Primary Health Care Research and Development 2007; 8: 3-11 
Table 2 Summary of the activities and achievements of the 17 departments of general practice and rural health in 2000 (before RCBI funding commenced) and 2003

\begin{tabular}{|c|c|c|c|c|}
\hline Categories & $\begin{array}{l}2000 \\
\text { (before funding commenced) } \\
\text { Activities and achievements }\end{array}$ & $\begin{array}{l}\text { Number of } \\
\text { Departments }\end{array}$ & $\begin{array}{l}2003 \\
\text { (second whole year of funding) } \\
\text { Activities and achievements }\end{array}$ & $\begin{array}{l}\text { Number of } \\
\text { Departments }\end{array}$ \\
\hline $\begin{array}{l}\text { Teaching in } \\
\text { academic } \\
\text { courses }\end{array}$ & $\begin{array}{l}\text { Undergraduate and post } \\
\text { graduate courses }\end{array}$ & 10 & $\begin{array}{l}\text { Undergraduate and post } \\
\text { graduate courses }\end{array}$ & 12 \\
\hline $\begin{array}{l}\text { Research } \\
\text { supervision/ } \\
\text { mentoring }\end{array}$ & $\begin{array}{l}41 \mathrm{PhD} \text { students } \\
30 \text { Masters students } \\
14 \text { people mentored }\end{array}$ & $\begin{array}{r}11 \\
9 \\
5 \\
2\end{array}$ & $\begin{array}{l}43 \mathrm{PhD} \text { students } \\
8 \text { Masters students } \\
266 \text { people mentored }\end{array}$ & $\begin{array}{r}17 \\
9 \\
4 \\
16\end{array}$ \\
\hline $\begin{array}{l}\text { Research } \\
\text { networks }\end{array}$ & NA & & $\begin{array}{l}22 \text { networks } \\
1377+\text { members }\end{array}$ & 13 \\
\hline $\begin{array}{l}\text { Research } \\
\text { educational } \\
\text { activities }\end{array}$ & $\begin{array}{l}103 \text { educational activities } \\
624+\text { participants }\end{array}$ & $\begin{array}{l}8 \\
8\end{array}$ & $\begin{array}{l}189 \text { educational activities } \\
3639+\text { participants } \\
\text { research use skill building } \\
\text { researcher skill building } \\
\text { evaluation activities } \\
\text { writing and presentation skills }\end{array}$ & $\begin{array}{r}17 \\
17 \\
12 \\
12 \\
11 \\
5\end{array}$ \\
\hline Collaborations & NA & & $\begin{array}{l}\text { Reasons for collaboration: as } \\
\text { part of a needs assessment, grant } \\
\text { applications, research projects or } \\
\text { educational activities }\end{array}$ & 17 \\
\hline $\begin{array}{l}\text { Research } \\
\text { funding }\end{array}$ & $\begin{array}{l}107 \text { grants totalling } \\
\$ 10,989,796+\end{array}$ & 12 & $\begin{array}{l}110 \text { grants totalling } \$ 15,655,546+ \\
\text { (external to RCBI) } \\
\text { PHCRED funded grants, bursaries, } \\
\text { fellowships, scholarships }\end{array}$ & $\begin{array}{l}15 \\
14\end{array}$ \\
\hline Research effort & $\begin{array}{l}178 \text { peer review papers } \\
\text { Conference presentations - NA }\end{array}$ & 10 & $\begin{array}{l}130 \text { peer review papers } \\
187 \text { conference presentations }\end{array}$ & $\begin{array}{l}12 \\
17\end{array}$ \\
\hline
\end{tabular}

In 2003, workshops were the most commonly reported activity, however regular group meetings, research clinics and seminar series also took place. Although most workshops were only offered once during the year, some departments repeated workshops on several occasions to meet the demand. Others offered a series of workshops on related issues.

Workshops for users of research (eg evidencebased practice, critical appraisal, $n=12$ ) and those focused on skill building (eg research methodology, developing research questions, $n=12$ ) were the most frequently reported. Workshops on evaluation $(n=11)$ and writing and presentation skills $(n=5)$ were also reported. Three departments presented workshops covering all of these areas.

Departments reported the production and dissemination of both print and electronic resources, including several web-based resources such as PHCRED websites and on-line courses and modules.
'In kind' support was varied and included PHCRED staff being members on committees or boards, journal review panels, working parties, promoting activities and resources, providing academic teaching and consultation.

\section{Collaborations}

In 2003, all departments reported some level of collaboration, either to develop grant applications, research projects or around educational activities. This information was not obtained for 2000. Collaborations were local, national and international, including other university departments, other universities, Divisions of General Practice (geographical groupings of general practices), health service providers, Aboriginal health services, consumer organizations/representatives, research and health service organizations and overseas organizations. 
Table 3 Distribution of research projects (based on project title) being undertaken by RCBI funded departments in 2003 by National Health Priorities (across) and Primary Health Care Research Priorities (down)

\begin{tabular}{|c|c|c|c|c|c|c|c|c|c|}
\hline 2003 & $\begin{array}{l}\text { Evidence- } \\
\text { based } \\
\text { practice }\end{array}$ & $\begin{array}{l}\text { Quality } \\
\text { of care }\end{array}$ & $\begin{array}{l}\text { Models } \\
\text { of service } \\
\text { delivery }\end{array}$ & Integration & $\begin{array}{l}\text { Economic } \\
\text { issues }\end{array}$ & $\begin{array}{l}\text { Health } \\
\text { inequalities }\end{array}$ & $\begin{array}{l}\text { Illness } \\
\text { prevention } \\
\text { and health } \\
\text { promotion }\end{array}$ & Unknown & Total \\
\hline $\begin{array}{l}\text { Cardiovascular } \\
\text { diseases }\end{array}$ & 1 & & 2 & & & 1 & 1 & & 5 \\
\hline Mental health & 7 & 3 & 1 & 2 & & & 3 & 2 & 18 \\
\hline Injury & 2 & 1 & 1 & & & & 3 & 2 & 9 \\
\hline Cancer & & 1 & & & & & & 1 & 2 \\
\hline Asthma & & 1 & 1 & 1 & & & 1 & & 4 \\
\hline Diabetes & & 1 & & & & & & & 1 \\
\hline Unknown & 9 & 9 & 10 & 5 & & 2 & 9 & 20 & 64 \\
\hline Total & 19 & 16 & 15 & 8 & 0 & 3 & 17 & 25 & 103 \\
\hline
\end{tabular}

Effective collaboration among RCBI funded university departments in four states (South Australia, Queensland, New South Wales, Victoria) resulted in state forums and seminars that provided new researchers the opportunity to present their research to and network with other primary health care professionals and academics in their state.

There was a substantial collaboration with Divisions of General Practice, with half (61/121) of the Divisions in Australia engaged in collaborative activity with the Departments receiving RCBI funding. All Divisions of General Practice in Northern Territory $(n=2)$, and Tasmania $(n=3)$ were mentioned in the annual reports, while $63 \%(n=19)$ of Divisions in Victoria, 60\% $(n=12)$ in Queensland, $50 \%(n=7)$ in South Australia, 43\% $(n=6)$ in Western Australia, and 32\% $(n=12)$ in New South Wales/Australian Capital Territory were mentioned.

\section{Research funding}

Fifteen of the 17 departments acquired over \$AUD15.6 million from 110 grants funding 103 research projects. This was an increase in research funding from \$AUD10.9 million in 2000. The mean success rate of grant applications and tender submissions was $69.2 \%$, ranging from $0 \%(0 / 7)$ to $100 \%(3 / 3)$ in the 11 departments where sufficient data were provided. In addition, 14 departments funded further research projects internally through using RCBI money to fund grants and bursaries, plus researcher support via fellowships and scholarships, something that had not been possible prior to 2001.

\section{Research effort}

Research effort as measured by the number of peer reviewed publications did not increase in 2003 compared to 2000. However, departments had been actively disseminating their work via 187 conference presentations in 2003.

The research conducted in 2003, whilst diverse, had an emphasis on the established primary health care research priorities. Table 3 shows the distribution of funded research projects according to National Health Priorities (National Health Priority Areas Initiative, 2006) and Primary Health Care Research Priorities (Kalucy et al., 2001). Allocation was made on the basis of project titles. It was only possible to allocate $38 \%$ of projects to National Health Priority areas and $75 \%$ to Primary Health Care Research Priority areas. Projects most commonly fell into the National Health Priority area of Mental Health $(n=18)$, while the most common Primary Health Care Research Priority areas researched were evidencebased practice $(n=19)$, illness prevention and health promotion $(n=17)$, quality of care $(n=16)$ and models of service delivery $(n=15)$. Less commonly researched Primary Health Care Research Priority areas were health inequalities, integration and economic issues.

\section{Discussion}

This document review of the 2003 annual reports from RCBI funded academic departments of general practice and rural health has shown a substantial Primary Health Care Research and Development 2007; 8: 3-11 
increase in most areas of research activity compared to 2000 , the year before this funding commenced.

\section{Education and training}

Training is a pivotal strategy for building research capacity and culture. The substantial increase in the number of research activities in RCBI funded departments in 2003 compared to 2000 indicates a willingness of RCBI funded staff to interact with the wider primary health care community to facilitate the building of a research culture in this sector. This has been complimented by an enthusiasm and willingness by participants to learn about undertaking and using research, as seen by the large number of attendees at these activities. Whether this skill building process has addressed specific research gaps remains to be seen. It is also too early to say how the educational activities will impact on primary health care research and future research utilization, although the review by McGrail et al. (2006) suggests that activities such as writing groups led to an increase in publication rates.

\section{Mentoring and supervision}

Significant effort was given to increase the mentoring and supervision of students and primary health care practitioners involved in research. While the total number of PhD students across the programme suggests that capacity is being built in the future leadership of primary health care research, this has yet to be realized in eight of the departments. Postgraduate support and supervision requires an infrastructure that is closely aligned with the expertise of key leaders in the field, something that may require development in these departments, particularly the more recently established departments.

The total amount of research mentoring of people not enrolled in a higher degree has increased dramatically both in the number of departments offering this service ( 2 in 2000 to 16 in 2003) and in the number of people involved (14 in 2000 to 266 in 2003). For many practitioner/researchers, this has provided an entree into research. Fostering practitioner driven research activity has the advantage of building research within practitioner's everyday work and is an expedient alternative to the conventional higher degree pathway. It also increases the likelihood of producing primary care relevant research in the short term and for smallscale projects (Lee and Saunders, 2004).

This ability to attract primary health care workers to conduct research is a strength of the RCBI. It is also a weakness as currently the PHCRED Strategy does not provide for a career pathway for mid-career academics to provide leadership to the new generation of researchers (Oceania Health Consulting, 2005).

\section{Networks and collaboration}

The number of research networks currently operating and the number of people these are attracting is indicative of the level of interest in research in the Australian primary health care community. Research networks enable effective collaboration between practitioners and researchers so that research is relevant, provides the opportunity to address research agendas and disseminates and implements research findings (Thomas et al., 2001). In the US, primary health care research networks were developed as a key strategy in promoting targeted research. Whilst no formal evaluation of this strategy has been published, in comparison to PHCRED, the US network strategy appears to be unable to achieve the programme reach of the RCBI (Burstin and Lanier, 2001).

Although the 2003 annual reports did not provide information about the network members' specific research backgrounds, the diversity of collaborations suggests that both researchers and practitioners are involved. Other authors (Pearson and Jones, 1997; Harrison, 2005; Whitford et al., 2005) however, highlight the fact that collaborations alone are insufficient. A culture has to be developed within primary health care teams or organizations which achieve jointly held aims for patient care. It will be interesting to monitor and explore how these collaborations affect the type and nature of primary health care and research in the future.

The RCBI has provided infrastructure support for research capacity building largely at the individual level, although increasingly at the team level. It is likely that a team approach, as discussed by Cooke and colleagues (Cooke et al., 2006) will be needed to enable 'critical mass' benefits.

Both Divisions of General Practice and university departments acknowledge the importance of collaborating in terms of their research and 
evaluation activity (Beacham et al., 2005). This collaboration is now also encouraged by the Australian Government (Australian Government, 2004). Half of the Divisions were collaborating with university departments which represents a substantial effort considering the challenges that collaborative research presents, and since Divisions of General Practice did not have research as core business (Beacham et al., 2005). With the changes to the Divisions' research activity requirements following the review (Australian Government, 2004), there is potential for more collaboration between university departments and Divisions of General Practice, with mutual benefits as yet unrealized.

\section{Diversity of research projects}

The diversity of research projects (Table 3 ), suggests that investigator driven research is flourishing, but also reveals gaps where research may not be happening. These gaps may indicate that there is an insufficient skill base or funding for research to be undertaken in these areas or the priorities may not be addressing areas where there is a primary health care research skill set. A more detailed analysis of the gaps in priority research, funding and skill base may answer this.

\section{Dissemination of research findings}

Dissemination of research findings is an important outcome for this initiative, and in 2003 all departments disseminated their research through conference presentations. However, peer reviewed papers (particularly in high-impact publications) for primary health care are desirable to the development of the discipline of primary health care. While some departments published multiple peer reviewed papers, others published very few. This may reflect the differing maturity levels of departments or that some departments disseminated their information primarily at a grassroots targeted level.

\section{Sustainability of infrastructure and output}

Developing a research culture has a long lead time, particularly for novice researchers. Some departments were funded with staff already researching and publishing, whilst others were still developing their research culture. Staffing issues, particularly staff changes and delays with appointments were evident in approximately half of the programmes. This is likely to have an impact on programme development. Frequent staff turnover is a common feature in non-continuing 'soft-money' programmes. This initiative offers limited capacity to provide certainty of employment to many staff beyond the short term. This has led to some instability in staffing which may have impeded the continuity of some research activities (Oceania Health Consulting, 2005). Given this, the documented level of research activity is all the more remarkable.

The RCBI's role has been somewhat similar to that of the UK's Research and Development Support Units. For the momentum to be maintained, we need to reflect on the underlying infrastructure support across the primary care sector. There is some evidence in the overseas literature that infrastructure support is essential for research capacity building. Kruse et al. (2003) identified three factors that positively correlated with increased research productivity: fellowship programmes to train researchers and programme directors; research strategic plans; and full-time research professionals in many more residency programmes. Departments funded through the RCBI have largely followed these strategies, having engaged a large number of people and conducted a diverse range of activities that contribute to both the building of capacity in using and undertaking research and evaluation, and contribute to the knowledge base in primary health care.

\section{Limitations}

This assessment of research capacity building activity can only be regarded as a brief comparison of research activity. Some researchers suggest that the assessment must include other factors. For example, Tomlinson has suggested that the current methods for assessing research output should not only include a count of the numbers of research staff and students as well as income from research grants, but also 'evidence of the department's vitality and prospects for continuing development' (Tomlinson, 2000: 637). These latter components are more difficult to assess. Others, such as Williams, argue that soft measures, including research grant income, are too unreliable and that 'publications are the only universally accepted currency of research success' (Williams, 1998: 1081). Clearly, the full 
impact of the RCBI will take some time to evolve and appropriate and measurable indicators of success need to be developed (Oceania Health Consulting, 2005).

There are some limitations in regards to the collation and interpretation of the data reported here. Unpacking RCBI activities (in the 2003 reports) from others occurring in university departments was not always straightforward, and coupled with varying interpretations of what to report by departments, made interpreting and summarizing the data challenging. Finally, as this analysis is a description of activities as reported by departments, there is the possibility that data may have been over or under-reported. Indeed, some departments did not report on all categories - whether this was because there was nothing to report or because the data had been removed prior to receipt by the researchers.

\section{Conclusions}

If the strength of primary health care research is considered a good indicator of the strength of quality of primary health care in a country, then Australia is moving in the right direction (Mant et al., 2004). The RCBI funding has generated considerable research capacity building activity in these departments of general practice and rural health around Australia. This has provided a major boost to primary health care research in Australia. These activities would have been unlikely to occur without the support and assistance of the PHCRED Strategy. Funding has been continued for the next 5 years, highlighting the growing understanding by government and academic institutions that partnerships to create a health and policy relevant primary health care research capacity in Australia is a long term prospect (PHC RIS, 2006).

\section{Statement of competing interest}

Ellen McIntyre, as part of the Primary Health Care Research and Information Service, is funded by the Primary Care Division of the Australian Government Department of Health and Ageing, to provide support for the PHCRED Strategy.

All other authors have been funded/partfunded through this initiative.

Primary Health Care Research and Development 2007; 8: 3-11

\section{Acknowledgements}

The authors wish to thank all who contributed to the writing of the reports used in this analysis, and the Australian Government Department of Health and Ageing for making these reports available.

\section{References}

Askew, D., Clavarino, A., Glasziou, P. and Del Mar, C. 2002: General practice research: attitudes and involvement of Queensland general practitioners. Medical Journal of Australia 177, 74-77.

Australian Government. 2004: Divisions of General Practice: Future directions. Government response to the report of the review of the role of Divisions of General Practice. April 2004. Retrieved September 2006 from http://www. health.gov.au/internet/wcms/publishing.nsf/Content/healthpcd-programs-divisions-index.htm/\$FILE/fut_dir.pdf

Beacham, B., Kalucy, L. and Lowcay B. 2003: How relevant are recently completed GPEP projects (1999-2001) to priorities for primary health care research, evaluation and development? Australian Family Physician 32, 377-80.

Beacham, B., Kalucy, L., Veale, B., Lowcay, B., Pearce, C. and Yates, R. 2005: What supports effective links between divisions of general practice and universities? Opportunity and fair relationships. Retrieved September 2006 from http:/ www.phcris.org.au/publications/catalogue.php?elibid $=1220$

Burstin, H. and Lanier, D. 2001: Update from funders. Center for primary care research and agency for health care research and quality. Medical Care 39, 309-11.

Cooke, J., Nancarrow, S., Hammersley, V., Farndon, L. and Vernon, W. 2006: The 'Designated Research Team' approach to building research capacity in primary care. Primary Health Care Research and Development 7, 78-86.

Department of Health and Aged Care. 1998: General practice strategy review group report. Canberra: Department of Health and Aged Care.

Department of Health and Aged Care. 1999: The virtuous cycle. working together for health and medical research: strategic review. Canberra: Department of Health and Aged Care. Retrieved September 2006 from http://www.health. gov.au/internet/wcms/publishing.nsf/Content/hmrsr.htm.

Dunbar, N., Comino, E., Mehmet, S. and Harris, M. 2002: Research capacity in general practice. Australian Family Physician 31, 205-207.

Farmer, L. and Pilotto, L. 2001: Capacity building in general practice research - Not a quick fix (editorial). Australian Family Physician, April 2001.

Gunn, J. 2002: Should Australia develop primary care research networks? Medical Journal of Australia 177, 63-66.

Harrison, R.A. 2005: Barriers and opportunities to developing research capacity in primary care trusts: the views of staff 
attached to a primary care trust Primary Health Care Research and Development 6, 185-89.

Jones, A., Burgess, T., Farmer, E., Fuller, J., Stocks, N., Taylor, J. and Waters, R. 2003: Building research capacity: an exploratory model of GP's training needs and barriers to research involvement. Australian Family Physician 32, 957-60.

Kalucy, L., Beacham, B., Raupach, J., Dwyer, J., and Pilotto, L. 2001: Priorities for primary health care research, evaluation and development in Australia. Final report - priority setting process: stage one, May 2001. Adelaide: Primary Health Care Research and Information Service.

Kruse, J., Bradley, J., Wesley, R. and Markwell, S. 2003: Research support infrastructure and productivity in US family practice residency programs. Academic Medicine 78, 54-60.

Lee, M. and Saunders, K. 2004: Oak trees from acorns? An evaluation of local bursaries in primary care. Primary Health Care Research and Development 4, 93-95.

Mant, D., Del Mar, C., Glasziou, P., Knottnerus, A., Wallace, P. and van Weel, C. 2004: The state of primary-care research. The Lancet 364, 1004-1006.

McGrail M., Rickard C. and Jones R. 2006: Publish or perish: a systematic review of interventions to increase academic publication rates. Higher Education Research and Development 25, 19-35.

National Health Priority Areas Initiative. 2006: Retrieved September 2006 from http://www.aph.gov.au/library/pubs/ cib/1999-2000/2000cib18.htm

Oceania Health Consulting. 2005: Summary report of the Primary Health Research, Evalaution and Development Strategy.
Retrieved September 2006 from http://www.phcris.org.au/ phcred/evaluation_report.php

Pearson, P. and Jones, K. 1997: Primary care - opportunities and threats. Developing professional knowledge: making primary care education and research more relevant. British Medical Journal 314, 817-20.

PHC RIS. 2006: PHCRED Strategy. Retrieved September 2006 from http://www.phcris.org.au/phcred/

RCBI. 2006: Research Capacity Building Initiative. Retrieved September 2006 from http://www.phcris.org.au/phcred/ rcbi.php

Shah, N., Pond, D. and Heaney S. 2002: Research capacity building in general practice. The new Australian scene. Australian Family Physician 31, 201-204.

Thomas, P., Griffiths, F., Kai, J. and O'Dwyer A. 2001: Networks for research in primary health care. British Medical Journal 322, 588-90.

Tomlinson, S. 2000: The research assessment exercise and medical research. British Medical Journal 320, 636-39.

Van Der Weyden, M.B. 2001: Australian general practice at a fork in the road: which way forward? Medical Journal of Australia 175, 62-63.

Whitford, D.L., Walker, C. and Jelley, D. 2005: Developing R\&D capacity in a primary care trust: use of the R\&D culture index. Primary Health Care Research and Development $6,185-89$.

Williams, G. 1998: Misleading, unscientific and unjust: the United Kingdom's research assessment exercise. British Medical Journal 316, 1079-82. 